\title{
Prevalensi age related macular degeneration di Poliklinik Mata BLU RSUP Prof. Dr. R. D. Kandou Manado periode Januari 2013 - Oktober 2015
}

\author{
${ }^{1}$ Clarissa E. Tany \\ ${ }^{2}$ Vera Sumual \\ ${ }^{2}$ J. S. M. Saerang
}

\author{
${ }^{1}$ Kandidat Skripsi Fakultas Kedokteran Universitas Sam Ratulangi Manado \\ ${ }^{2}$ Bagian Ilmu Kesehatan Mata Fakultas Kedokteran Universitas Sam Ratulangi \\ RSUP Prof. Dr. R. D. Kandou Manado \\ Email: clarissatany@gmail.com
}

\begin{abstract}
Age-related macular degeneration (AMD) is a visual impairment in central area of the retina (macula) that tends to be progressive. In developing countries, AMD becomes the most common cause of irreversible vision loss in people aged $\geq 50$ years. This study aimed to obtain the prevalence of AMD in Department of Opthalmology at Prof. Dr. R. D. Kandou Hospital Manado from January 2013 to October 2015. This was a descriptive retrospective study using medical records of Department of Opthalmology. The results showed that there were 41 patients diagnosed as AMD. Based on sexes, AMD occured more frequent in male patients as many as 28 paients (68.3\%). This disease was dominated by patients aged 61-70 years old as many as 16 patients (39\%). There were 10 patients $(24.4 \%)$ that had history of hypertension.
\end{abstract}

Keywords: prevalence, AMD

\begin{abstract}
Abstrak: Age-related macular degeneration (AMD) adalah suatu gangguan penglihatan sentral retina (makula) yang bersifat progresif. Di negara berkembang AMD menjadi penyebab terbanyak hilangnya penglihatan yang ireversibel pada individu di atas 50 tahun. Penelitian ini bertujuan untuk mengetahui prevalensi AMD di Poliklinik Mata BLU RSUP Prof. Dr. R. D. Kandou Manado periode Januari 2013-Oktober 2015. Jenis penelitian ini deskriptif retrospektif dengan memanfaatkan data rekam medik di Poliklinik Mata BLU RSUP Prof. Dr. R. D. Kandou Manado. Hasil penelitian memperlihatkan 41 pasien dengan diagnosis AMD. Berdasarkan jenis kelamin, AMD lebih banyak dialami oleh jenis kelamin laki-laki sebanyak 28 orang (68,3\%), sedangkan untuk rentang umur didominasi oleh umur 61-70 tahun yaitu sebanyak 16 orang (39\%). Terdapat 10 orang (24,4\%) dengan riwayat hipertensi.
\end{abstract}

Kata kunci: prevalensi, AMD

Age-related Macular Degeneration (AMD) adalah suatu gangguan penglihatan sentral retina (makula) yang bersifat progresif yang terjadi pada populasi usia 50 tahun atau diatas 50 tahun. $^{1-3}$ Jika dibawah 50 tahun dipertimbangkan suatu distrofi macular herediter dengan gejala klinis yang menyerupai AMD. ${ }^{1}$

Prevalensi kelainan pada retina di Indonesia mencapai $0,13 \%$ dan merupakan penyebab kebutaan ke empat setelah katarak, glaukoma dan kelainan refraksi. Hal ini diketahui berdasarkan Survei Kesehatan Indra Penglihatan dan Pendengaran. ${ }^{4}$ Di dunia, penderita AMD diperkirakan telah mencapai 20-25 juta jiwa yang akan bertambah tiga kali lipat akibat peningkatan usia lanjut dalam waktu 30-40 tahun mendatang. ${ }^{5}$ Menurut WHO, salah satu penyebab terbanyak kebutaan di 
Tany, Sumual, Saerang: Prevalensi age related...

dunia ialah degenerasi makula terkait usia yang menempati urutan ke-4 sebesar $7 \%$ dan WHO memperkirakan 8 juta orang akan mengalami kebutaan akibat AMD.,6 Di negara berkembang, AMD menjadi penyebab terbanyak hilangnya penglihatan yang ireversibel pada individu $>50$ tahun. ${ }^{4}$

Salah satu penelitian dari Fakultas Kedokteran Universitas Indonesia periode 3 Maret 2008 - 5 Januari 2009 di Jakarta Timur, yang menggunakan 1259 responden melaporkan prevalensi AMD non eksudatif sebanyak 52 orang $(4,1 \%)$ dan eksudatif sebanyak 3 orang $(0,2 \%)$. Prevalensi AMD didapatkan semakin meningkat dengan bertambahnya usia, dimana $3,4 \%$ pada kelompok usia 40-49 tahun, 4,8\% pada kelompok usia 50-59 tahun, dan 7,4\% pada usia $>70$ tahun. $^{7}$

Penelitian ini bertujuan untuk mendapatkan prevalensi AMD di Poliklinik Mata BLU RSUP Prof. Dr. R. D. Kandou Manado.

\section{METODE PENELITIAN}

Jenis penelitian ini deskriptif retrospektif dengan menggunakan data rekam medik di Poliklinik Mata BLU RSUP Prof. Dr. R. D. Kandou Manado periode Januari 2013 - Oktober 2015. Subjek penelitian ialah data rekam medik pasien yang didiagnosis Age Related Macular Degeneration (AMD).

\section{HASIL PENELITIAN}

Berdasarkan hasil penelitian di Poliklinik Mata BLU RSUP Prof. Dr. R. D. Kandou Manado periode Januari 2013 Oktober 2015 didapatkan 41 penderita yang didiagnosis AMD. Tabulasi dilakukan menurut jenis kelamin, usia, jenis AMD, dan faktor risiko.

Tabel 1. Distribusi AMD berdasarkan jenis kelamin

\begin{tabular}{ccc}
\hline $\begin{array}{c}\text { Jenis } \\
\text { Kelamin }\end{array}$ & Jumlah & $\%$ \\
\hline Laki - laki & 28 & 68,3 \\
Perempuan & 13 & 31,7 \\
Total & 41 & 100 \\
\hline
\end{tabular}

Tabel 2. Distribusi AMD berdasarkan Usia

\begin{tabular}{ccc}
\hline Umur & Jumlah & $\%$ \\
\hline$\leq 50$ tahun & 4 & 9,8 \\
$51-60$ tahun & 10 & 24,4 \\
$61-70$ tahun & 16 & 39,0 \\
$71-80$ tahun & 8 & 19,5 \\
$\geq 81$ tahun & 3 & 7,3 \\
Total & 41 & 100 \\
\hline
\end{tabular}

Tabel 3. Distribusi AMD berdasarkan Jenis AMD

\begin{tabular}{ccc}
\hline Jenis AMD & Jumlah & $\%$ \\
\hline AMD kering & 28 & 68,3 \\
AMD basah & 10 & 24,4 \\
AMD kering + & 3 & 7,3 \\
AMD basah & & \\
Total & 41 & 100 \\
\hline
\end{tabular}

Tabel 4. Distribusi AMD berdasarkan Faktor Risiko

\begin{tabular}{ccc}
\hline Faktor risiko & Jumlah & $\%$ \\
\hline DM & 3 & 7,3 \\
Hipertensi & 10 & 24,4 \\
DM + Hipertensi & 4 & 9,75 \\
Tanpa faktor risiko & 4 & 9,75 \\
Tidak teridentifikasi & 20 & 48,8 \\
Total & 41 & 100 \\
\hline
\end{tabular}

\section{BAHASAN}

Berdasarkan hasil penelitian di Poliklinik Mata BLU RSUP Prof. Dr. R. D. Kandou Manado periode Januari 2013 Oktober 2015 yang dilakukan pada bulan September 2015 - Desember 2015 maka didapatkan 41 penderita AMD yang datang berobat di Poliklinik Mata.

Berdasarkan jenis kelamin didapatkan pasien AMD berjenis kelamin laki-laki lebih banyak daripada perempuan (Tabel 1). Hasil ini tidak sesuai dengan penelitian Singare et al. ${ }^{8}$ yang mendapatkan bahwa jenis kelamin perempuan lebih banyak dibandingkan laki-laki. Hal ini mungkin disebabkan pasien yang datang ke poliklinik mata lebih banyak yang berjenis kelamin laki-laki dibandingkan perempuan.

Berdasarkan rentang usia didapatkan pasien AMD terbanyak ialah dengan rentang usia 61-70 tahun sebanyak 16 orang (39\%). Hasil ini sesuai dengan 
definisi dari National Eye Institute ${ }^{9}$ bahwa AMD terjadi pada usia 60 tahun atau lebih tua. Juga tidak jauh berbeda dengan prevalensi dari Deloitte Macular Degeneration Foundation bahwa AMD meningkat pada umur 65 tahun. ${ }^{10}$ Untuk diagnosis AMD pada pasien yang berusia $\leq$ 50 tahun hanya didapatkan sebanyak 4 pasien (9,8\%). Hasil ini sesuai dengan teori dari Best Practice Advocacy Centre New Zealand bahwa AMD jarang didapatkan pada pasien dengan usia $\leq 50$ tahun. $^{11}$ Ketiga teori di atas sesuai dengan definisi dari Deloitte Macular Degeneration Foundation bahwa AMD biasanya didapatkan pada usia $\geq 50$ tahun. $^{10}$ Dari hasil penelitian yang dilakukan pada umur $\geq 81$ tahun didapatkan paling sedikit yaitu hanya 3 penderita (7,3\%). Hal ini berbeda dengan hasil penelitian dari Elvioza et al. ${ }^{7}$ dan Singare et al. ${ }^{8}$ bahwa prevalensi AMD didapatkan semakin meningkat dengan bertambahnya usia.

Berdasarkan diagnosis jenis AMD didapatkan pasien dengan jenis AMD kering yang tersering, yaitu sebanyak 28 penderita (68,3\%). Untuk AMD basah hanya didapatkan sebanyak 10 penderita (24,4\%) sedangkan gabungan AMD kering dan AMD basah didapatkan paling sedikit yaitu sebanyak 3 penderita (7,3\%). Hasil penelitian ini tidak berbeda jauh dengan pendapat Ilyas dan Yulianti, $^{12}$ serta American Optometric Association ${ }^{13}$ yang menuliskan bahwa AMD kering lebih banyak ditemukan pada pasien yang didiagnosis AMD yaitu sebanyak 70-90\% dibandingkan dengan AMD basah yang hanya $10 \%{ }^{1}$

Berdasarkan faktor risiko persentase tertinggi ialah hipertensi yaitu sebanyak 10 pasien (24,4\%). Hasil penelitian ini sesuai dengan hasil penelitian dari American Academy of Opthalmology dimana didapatkan adanya hubungan antara AMD dengan hipertensi. ${ }^{1}$ Hipertensi juga menjadi salah satu faktor risiko yang memiliki hubungan kuat dengan AMD, yang sesuai dengan hasil penelitian Chakravarthy et al. ${ }^{14}$. Pada penelitian ini yang didapatkan paling sedikit yaitu dengan faktor risiko
DM sebanyak 3 pasien (7,3\%). Menurut Erke, ${ }^{15}$ beberapa penelitian menemukan adanya hubungan AMD dengan DM tapi tidak pada semua penelitian. Menurut Chakravarthy, ${ }^{14} \mathrm{DM}$ merupakan salah satu faktor risiko yang lemah dan tidak pasti berhubungan dengan terjadinya AMD. Menurut Jae et al. ${ }^{16,17}$ terdapat hubungan antara early AMD dan DM. Walaupun demikian, banyak penelitian yang tidak menemukan hubungan bermakna antara AMD dan DM, sebagai contoh the Blue Mountain Eye Study menemukan bahwa atrofi geografik memiliki hubungan bermakna dengan DM, tetapi tidak menemukan hubungan antara AMD neovaskuler atau early AMD dengan DM. ${ }^{18}$ Berbeda halnya dengan EUREYE studi yang menemukan adanya hubungan positif antara AMD neovaskuler dan DM. ${ }^{19}$

\section{SIMPULAN}

Berdasarkan hasil penelitian penderita Age-related Macular Degeneration di Poliklinik Mata BLU RSUP Prof. Dr. R. D. Kandou Manado periode Januari 2013 Oktober 2015 dapat disimpulkan sebagai berikut:

1. Terdapat 41 penderita dengan diagnosis AMD.

2. Penderita AMD berjenis kelamin lakilaki lebih banyak dibandingkan yang berjenis kelamin perempuan.

3. Rentang usia 61-70 tahun yang paling sering ditemukan (39\%).

4. AMD kering merupakan jenis AMD yang paling banyak ditemukan

5. Hipertensi merupakan faktor risiko tersering

6. Yang paling banyak mempunyai faktor risiko hipertensi ialah penderita dengan rentang usia 61-70 tahun.

\section{SARAN}

1. Perlu dilakukan penelitian lanjut mengenai AMD yang berhubungan dengan penyakit sistem endokrin, pajanan sinar matahari, dan penggunaan aspirin.

2. Untuk dokter - dokter spesialis mata agar dapat memberikan sosialisasi 
Tany, Sumual, Saerang: Prevalensi age related...

kepada masyarakat mengenai AMD dan faktor - faktor risiko yang berhubungan dengan AMD serta menyarankan masyarakat terlebih lagi yang berusia lanjut untuk rajin melakukan kontrol ke dokter yang berkompeten.

3. Untuk penderita AMD agar rutin menjalani pengobatan untuk mencegah terjadinya progresifitas AMD.

4. Untuk Poliklinik Mata agar meningkatkan mutu dan kelengkapan data rekam medik.

\section{DAFTAR PUSTAKA}

1. American Academy of Ophthalmology The Eye MD Association. Age - Related Macular Degeneration. 2015 Januari [cited 2015 September 20].

2. Emory Eye Center. Vitamins and AgeRelated Macular Degeneration. 2014 January [cited 2015 September 20].

3. Prince Court Medical Centre. Program 'Sayangi Matamu' sebagai bagian dari Tanggung Jawab Sosial Perusahaan Prince Court Medical Centre (PCMC).

4. Tinjauan Pustaka Universitas Sumatera Utara. [cited: 2015 September 20].

5. Departemen Kesehatan RI. Age - Related Macular Degeneration. 2012 [cited 2015 September 20].

6. Global facts about blindness and visual impairment. International Agency for the Prevention of Blindness. 2010. [cited: 2015 September 2015].

7. Elvioza et al. Prevalensi dan Karakteristik Faktor Risiko Pada Kejadian Age Related Macular Degeneration di Jakarta Timur. [cited 2015 September 20]. Available from: http://mru.fk.ui.ac.id/index.php?uPage $=$ profil.profil_detail\&smod=profil\&sp =public\&idp\%20enelitian $=1498$

8. Singare RP, Deshmukh S, Ughade SN, Thakre SB. Age - Related Macular Degeneration: Prevalence and Risk factors in elderly population (Aged > 60 years) in Central India. International Journal of Scientific and Research Publications. 2015;5:2. [cited 2015 December 21].

9. National Eye Institute. Age - Related Macular Degeneration What Should You Know. 2014 September [cited 2015
September 20].

10. Mitchell P. Eyes on the future A clear outlook on Age-related Macular Degeneration. Deloitte. 2011;146:12,20. [cited 2015 December 21].

11. BPJ. Age - Related Macular Degeneration What should a general practitioner know? 2015 September [cited 2015 December 21].

12. Sidarta Ilyas HS, Yulianti SR. Mata Tenang Penglihatan Turun Perlahan. Ilmu Penyakit Mata (5th ed). Jakarta: FKUI, 2014; 239-40.

13. American Optometric Association. Care of the patient with Age-Related Macular Degeneration. 2004 [cited 2015 September 20]. Available from: https://www.aoa.org/documents/CPG6.pdf

14. Chakravarthy U, Wong TY, Fletcher A, Piault E, Evans Ch, Zlateva G, et al. Clinical risk factors for age-related macular degeneration: a systematic review and meta-analysis. BioMed Central. 2010 December 13 [cited 2016 January 20]. Available from: http://bmcophthalmol.biomedcentral.c om/articles/10.1186/1471-2415-10-31

15. Erke MG. Age-related macular degeneration: Prevalence and risk factors - a cross-sectional study [Disertasi]. [North Norway]: Univerity of Tromso; 2013.

16. Jae KC, Youl LL, Jun WM, Hyun JS, Cho B. Diabetes mellitus and eEarly Age-related Macular Degeneration. JAMA Opthalmology. 2011 February 14. [cited 2016 January 20]. Available from:

http://archopht.jamanetwork.com/articl e. aspx?articleid $=426940$

17. Ashton A. Macular Degeneration. Advances in Retinal Degeneration Research and Treatment (12th ed). Scholarly Editions, 2012; p. 69. 2012 December 26 [cited 2016 January 20]. Available from: https://books.google.co.id/books?id=q UviFHmgynAC\&pg=PA69\&lpg=PA6 9\&dq $=$ amd + and + diabetic + journal \&so urce $=$ bl\&ots $=$ aDoEH4guSO\&sig $=$ R19 uSC3YjxseuX2kPkJW7MYo_bo\&hl= id\&sa=X\&ved=0ahUKEwjawnWzbfKAhWECI4KHdSpBos4FBDo 
AQg6MAQ\#v=onepage\&q=amd\%20a nd\%20diabetic\%20journal\&f=false

18. Lim JI. Risk Factors for age - related macular degeneration and choroidal neovascularization. Age - Related Macular Degeneration (3rd ed). Boca Raton: CRC Press Taylor and Francis Group, 2013; p. 58. [cited 2016 January 20]. Available from: https://books.google.co.id/books?id=7 bTNBQAAQBAJ\&pg=PA62\&lpg $=\mathrm{P}$ A62\&dq=age+related+macular+degen eration+with+diabetic+risk+factors\&s ource $=$ bl\&ots $=$ kwNq72vakw\&sig $=\mathrm{Jw}$ gXZlQHn21hE9dBnKwsHzCqfYU\&h $\mathrm{l}=\mathrm{id} \& \mathrm{sa}=\mathrm{X} \& \mathrm{ved}=0 \mathrm{ahUKEwjNw7701}$ bfKAhUCUI4KHZwLAxg4ChDoAQ g6MAQ\#v=onepage\&q=age\%20relate d\%20macular\%20degeneration\%20wi th\%20diabetic\%20risk\%20factors\&f= false

19. Topouzis F, Anastasopoulos E, Augood C, Bentham GC, Chakravarthy U, de Jong PTVM, et al. Association of diabetes with age-related macular degeneration in the EUREYE study. British Journal of Opthalmology. 2009 May 7. [cited 2016 January 20]. Available from: http://bjo.bmj.com/content/93/8/1037. 